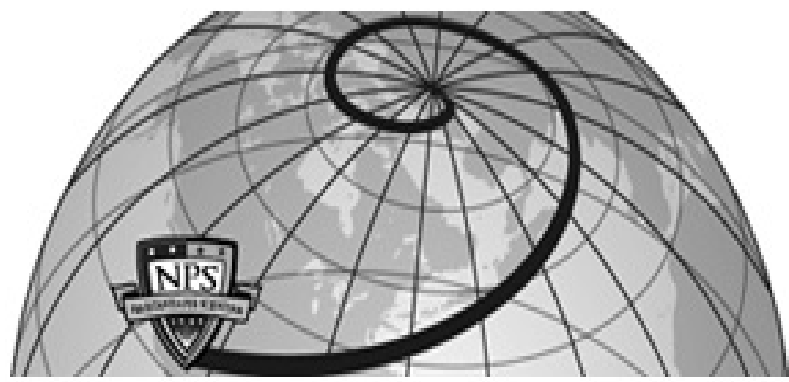

Calhoun: The NPS Institutional Archive DSpace Repository

\title{
Software productivity: potential, actual, and perceived
}

\author{
Abdel-Hamid, Tarek K.; Madnick, Stuart
}

System Dynamics Review, Volume 5, No. 2, Summer 1989, pp. 93-113. ISSN 0883-7066

https://hdl.handle.net/10945/43634

This publication is a work of the U.S. Government as defined in Title 17, United States Code, Section 101. Copyright protection is not available for this work in the United States.

Downloaded from NPS Archive: Calhoun

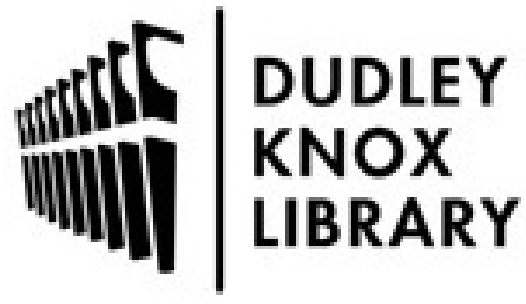

http://www.nps.edu/library
Calhoun is the Naval Postgraduate School's public access digital repository for research materials and institutional publications created by the NPS community. Calhoun is named for Professor of Mathematics Guy K. Calhoun, NPS's first appointed -- and published -- scholarly author.

Dudley Knox Library / Naval Postgraduate School 411 Dyer Road / 1 University Circle Monterey, California USA 93943 


\section{Software productivity: potential, actual, and perceived}

Tarek K. Abdel-Hamid and Stuart Madnick

In this article, we investigate the dynamics of software development productivity throughout the software development lifecycle. Our investigation discerns three forms of productivity, namely, potential, actual, and perceived. This conceptual dissection of productivity provides a useful lens for focusing on two distinct sets of managerial concerns: losses in the efficiency of software production, and losses in the effectiveness of managerial control. Losses in production efficiency stem from faulty processes associated with motivation and communication and lead to a gap between potential productivity and actual productivity. Losses in the effectiveness of managerial control arise, particularly in the early stages of a software project, from the discrepancy between what management perceives productivity to be and what it actually is.
The impressive improvements being made in the cost effectiveness of computer hardware are causing an enormous expansion in the number of applications for which computing is becoming a feasible and economical solution. This, in turn, is creating greater and greater demands for the development and operation of computer software systems. A conservative estimate suggests a hundredfold increase in the demand for software between 1965 and 1985 (Musa 1985).

While the growth in demand for software has been rapid, actual software development is increasing much more slowly. Musa (1985) estimates that U.S. software production capacity increased about eighteenfold between 1965 and 1985. Such a severe supply-demand imbalance is cause for serious concern. If it persists, it can have a debilitating effect, not only on the fledgling software industry but also on technological and economic development in many other areas of the economy.

The challenge posed to the software industry is to enhance the productivity of software development. An important prerequisite for accomplishing this is to gain an understanding of those factors that have a significant impact on software productivity. It is in pursuit of this goal that this article was written. Specifically, our objective is to provide a dynamic perspective of software productivity, examining those factors influencing it throughout the lifecycle of a software project.

\section{System dynamics modeling of project management}

The significance and applicability of the feedback systems concepts of system dynamics to project management has been substantiated by a large number of studies. One of the earliest is Roberts's (1964) published doctoral dissertation, which involved the development of a comprehensive system dynamics model of R\&D project management. The model traces the full lifecycle of a single R\&D project and incorporates the interactions between the R\&D product, the firm, and the customer. Nay (1965) and Kelly (1970) extended Roberts's work in their research on multiproject environments. Richardson (1982) took a different tack, focusing on the development group. His model reproduces the dynamics of a development group over an eight-year period as a continuous stream of products are developed and placed into production. The model traces the number of products under development, the use of resources required, and the product development time.

Several other models have been developed that emphasize the role of rework in project management. Cooper (1980), for example, describes a large system dynamics study of cost overruns in a shipbuilding contract for the U.S. Navy. The study showed that the rework required by frequent design changes imposed by the Navy was the major contributing factor to a $\$ 500$-million overrun. Undiscovered rework was also

We appreciate the contributions of several people who provided perspectives and data for this research effort. We especially thank John Sterman, Andy Ford, and the anonymous reviewers, whose suggestions helped us improve this article's readability. The work described here was supported in part by NASA research grant NAGW-448.

System Dynamics Review 5 (no. 2, Summer 1989): 93-113. ISSN 0883-7066. (c) 1989 by the System Dynamics Society. 
Tarek K. AbdelHamid is assistant professor of information systems in the Department of Administrative Sciences at the Naval Postgraduate School. He received the B.S. degree in aeronautical engineering from Cairo University in 1972 and the Ph.D. degree in management information systems from the Massachusetts Institute of Technology in 1984. His research interests focus on software project management, system dynamics, expert simulators, and management information svitems. Since 1986 he has been an adviser to NASA's Jet Propulsion Laboratory on the development of computerbased tools for software project management, and he is coauthor, with Stuart Madnick, of a forthcoming book Software Project Management

Stuart Madnick is professor of management science/information technology at the M.I.T. Sloan School of Management, an affiliate member of the M.I.T. Laboratory for Computer Science, liaison professor in the M.I.T. Leaders for Manufacturing Program, a member of the Research Advisory Committee of the International Financial Services Re- the focus of the simple R\&D models in Roberts (1978) and Richardson and Pugh (1981).

While the bulk of the system dynamics modeling work in project management has been devoted to the R\&D environment, the applicability of the methodology to the domain of software production has also been suggested, for example, by Graham (1982); Lehman (1978); Putnam (1980); and Snyder and Cox (1985). Perhaps this should come as no surprise, since the environments of R\&D project work and of software development have much in common:

In both cases, heavy expenditures are required in order to produce future benefits that are very uncertain in their magnitude. ... The stages of research and development are similar in many respects to the stages of software analysis and design. First, the determination of what the system is to do (specification of outputs and inputs) is very illdefined, making the estimation of the time and cost of its development uncertain (like the research stage). Second, the specification of how inputs are to be converted to outputs (file specification, programming) is easier to estimate (like the development state). These similarities suggest that a good many managerial practices and procedures from the latter be applied to the former. (Gehring and Pooch 1977)

In the remaining sections of this article, we demonstrate how the system dynamics approach to modeling R\&D project management can be extended to the software project domain.

\section{A system dynamics model of software development}

Our study of software productivity is being conducted within the context of a much broader research effort to study, gain insight into, and make predictions about the dynamics of the entire software development process. A major part of this effort has been devoted to developing a comprehensive system dynamics computer model of software development.

The model was developed on the basis of 27 field interviews of software project managers in five organizations. These were supplemented by empirical findings gathered from the literature.

\section{Scope of the model}

The domain of our model is that of medium-sized projects generating between 15,000 and 100,000 lines of code in contrast to either small one-programmer-type projects or superlarge projects involving hundreds of software professionals working over a period of several years. Within this domain, our study focuses entirely on the development processes (designing, coding, reviewing, and testing) of software production and does not examine the operation and maintenance phases, which follow development. The requirements definition phase, which precedes development, is also excluded from consideration, because we are concerned primarily with the software development organization, that is, with project managers and software development professionals and their policies, decisions, and actions. The definition of user re- 
search Center, and a member of the Exec utive Committee of the Center for Information Systems Research. His current research interests include interorganizational federated information systems, database technology, and software project management. Professor Madnick has authored or coauthored over 200 books, articles, and reports, including the widely used McGraw-Hill textbook Operating Systems. He edited The Strategic Use of Information Technology, published by Oxford University Press in 1987. Address: Sloan School of Management, E53317, M.I.T., Cambridge, MA 02139 , U.S.A.

Fig. 1. Overview of the model's four sectors quirements is excluded because, in many environments, this activity lies beyond the control of the software development group (McGowan and McHenry 1980).

\section{Model sectors}

The model's formulation integrates the multiple functions of the software development process, including both the management-type functions (e.g., planning, controlling, and staffing) and the software production-type activities (e.g., designing, coding, reviewing, and testing). Figure 1 depicts the model's four major sectors, namely: (1) the Human Resource Management Sector; (2) the Software Production Sector; (3) the Controlling Sector; and (4) the Planning Sector.

Because the model is quite comprehensive and highly detailed (156 level equations), it is infeasible to explain it fully in this article. We therefore limit our description to a high-level overview of the four sectors. The software productivity structure, which is our focus here, is discussed in detail later. (For a full description of the model's structure and mathematical formulation, see Abdel-Hamid 1984; AbdelHamid and Madnick 1989.)

The Human Resource Management Sector captures the hiring, training, assimilation, and transfer of the project's human resources. Such actions are not carried out in vacuum but, as Figure 1 suggests, are affected by the other sectors. For example, the project's hiring rate is a function of the workforce level needed to complete the project on a certain planned completion date. Similarly, the availability of workforce has direct bearing on the allocation of workers among the different software production activities in the Software Production Sector.

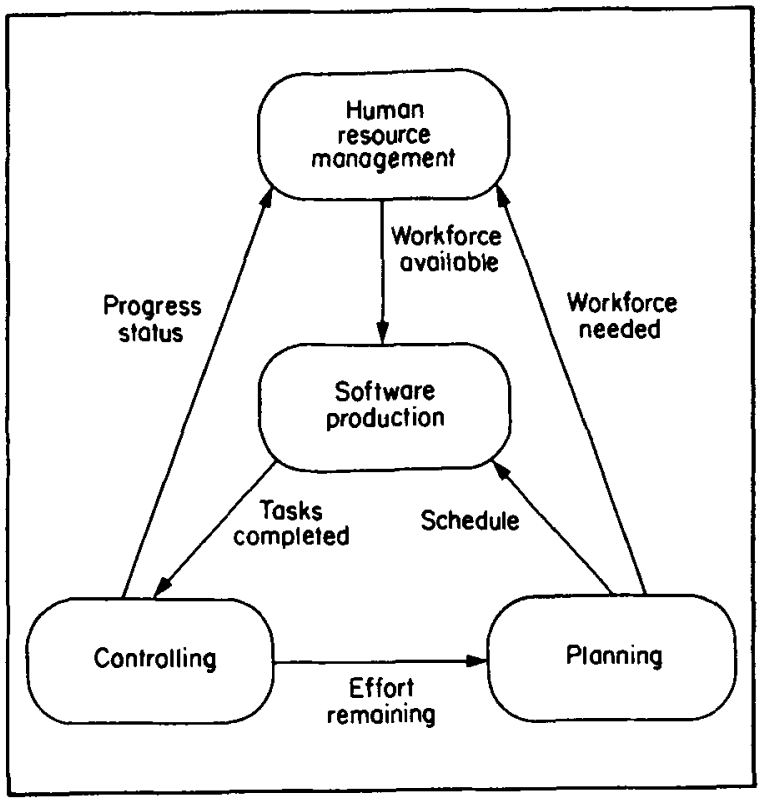


The four primary activities in the Software Production Sector are development, quality assurance, rework, and testing. The development activity comprises both the design and coding of the software. As the software is developed, it is also reviewed to detect errors. for example, by structured walkthroughs. Errors detected through such quality assurance activities are then reworked. Not all errors get detected and reworked, however. Some escape detection until the system testing phase.

As progress is made, it is reported. A comparison of where the project is versus where it should be according to plan is a control-type activity captured within the Controlling Sector. Once an assessment of the project's status is made, it becomes an important input to the planning function.

In the Planning Sector, initial project estimates are made at the beginning of the project, and then these estimates are reviewed, when necessary, throughout the project's life. For example, to handle a project that is perceived to be behind schedule, plans can be revised to (among other things) hire more people, extend the schedule, or do a little of both.

\section{Modeling the dynamics of software development productivity}

Defining the unit of software development productivity

Productivity may be expressed in tasks per man-day. In principle, a task may be any arbitrary unit for measuring a software project's size-it could be defined in terms of lines of code, function points, modules, or input/output files. From a practical point of view, though, defining a task in terms of delivered source instructions (DSI) is the most attractive alternative (Boehm 1981), and this is the definition we chose to use. Delivered source instructions are the actual computer-programming source instructions in the completed product, including job control language, format statements, and data definitions. They exclude comments and nondelivered support software like test programs. To model different project environments, we fixed the value of the nominal potential productivity parameter to be one task per man-day and adjusted the definition of a task.

Let us provide an example to illustrate how the definition of a task for an organization may be determined. Assume two different software development organizations, ORG-1 and ORG-2, have each just completed the development of some software project, PROJ-1 and PROJ-2, respectively. Further assume that the two projects are different in nature except that they are both exactly 8,000 delivered source instructions (DSI) in size. Suppose that in ORG-1 the development effort consumed a total of 400 man-days, while in ORG-2 the development effort took only 200 man-days. If, for the purposes of simplification, we assume that actual productivity is equal to potential productivity, we may conclude that the potential productivity in ORG-1 is half that of ORG-2. (The concepts of potential and actual productivity are explained in detail in the next section.) The nominal potential productivity parameter is set, in both cases, at one task per man-day. But, to model these different project environments, we would define a task to be 20 DSI for ORG-1 and 40 DSI for ORG-2. Thus, the 8,000 DSI PROJ-1 would be defined as a 400 -task project, while the 8,000 DSI 
PROJ-2 would be defined as a 200-task project. In other words, a task is defined as the potential daily output of an experienced and "up-to-speed" worker.

\section{Potential versus actual productivity}

Figure 2 presents the portion of the model in which actual software development productivity is formulated. This structure is based, in part, on a model of group productivity proposed by the psychologist Ivan Steiner (1972):

Actual productivity $=$ Potential productivity - Losses due to faulty process

where "losses due to faulty process" refers to a group's communication and motivation losses. Steiner (1972) explains:

Potential productivity is defined as the maximum level of productivity that can occur when an individual or group employs its funds of resources to meet the task demands of a work situation. It is the level of productivity that will be attained if the individual or group makes the best possible use of its resources (that is, if there is no loss of productivity due to faulty process). . . . Potential productivity can be inferred from a thorough analysis of task demands and available resources, for it depends only upon these two types of variables.

Actual productivity, what the individual or group does in fact accomplish, rarely equals potential productivity. Individuals and groups usually fail to make the best possible use of their available resources. Problems of coordination and/or motivation are responsible for inadequacies in process, and for consequent losses in productivity.

POTENTIAL PRODUCTIVITY. According to Steiner, potential productivity POTPRD is a function of two groups of factors, namely, the nature of the task and the project team's resources. Much of the research on software productivity has focused on identifying and investigating such factors. Table 1 summarizes the findings of a number of studies.

Notice that while most of the factors in Table 1 do vary from organization to organization (for example, availability of software tools, personnel capability, and computer hardware characteristics) and from project to project within a single organization (for instance, programming language, database size, and product complexity),

Table 1. Factors

affecting software productivity

\begin{tabular}{lll}
\hline Researchers & Nature of task & Group resources \\
\hline Scott and Simmons (1974) & $\begin{array}{l}\text { Programming language, quality of ex- } \\
\text { ternal documentation }\end{array}$ & $\begin{array}{l}\text { Availability of programming practices, } \\
\text { availability of programming tools, pro- } \\
\text { grammer experience }\end{array}$ \\
Chrysler (1978) & $\begin{array}{l}\text { Source language, computer hardware, } \\
\text { problem characteristics }\end{array}$ & $\begin{array}{l}\text { Programmer characteristics, organiza- } \\
\text { tional characteristics, programming } \\
\text { mode }\end{array}$ \\
Boehm (1981) & $\begin{array}{l}\text { Product complexity, required reliabil- } \\
\text { ity, memory constraints, database size }\end{array}$ & $\begin{array}{l}\text { Software tools used, turnaround time, } \\
\text { personnel experience }\end{array}$ \\
\hline
\end{tabular}




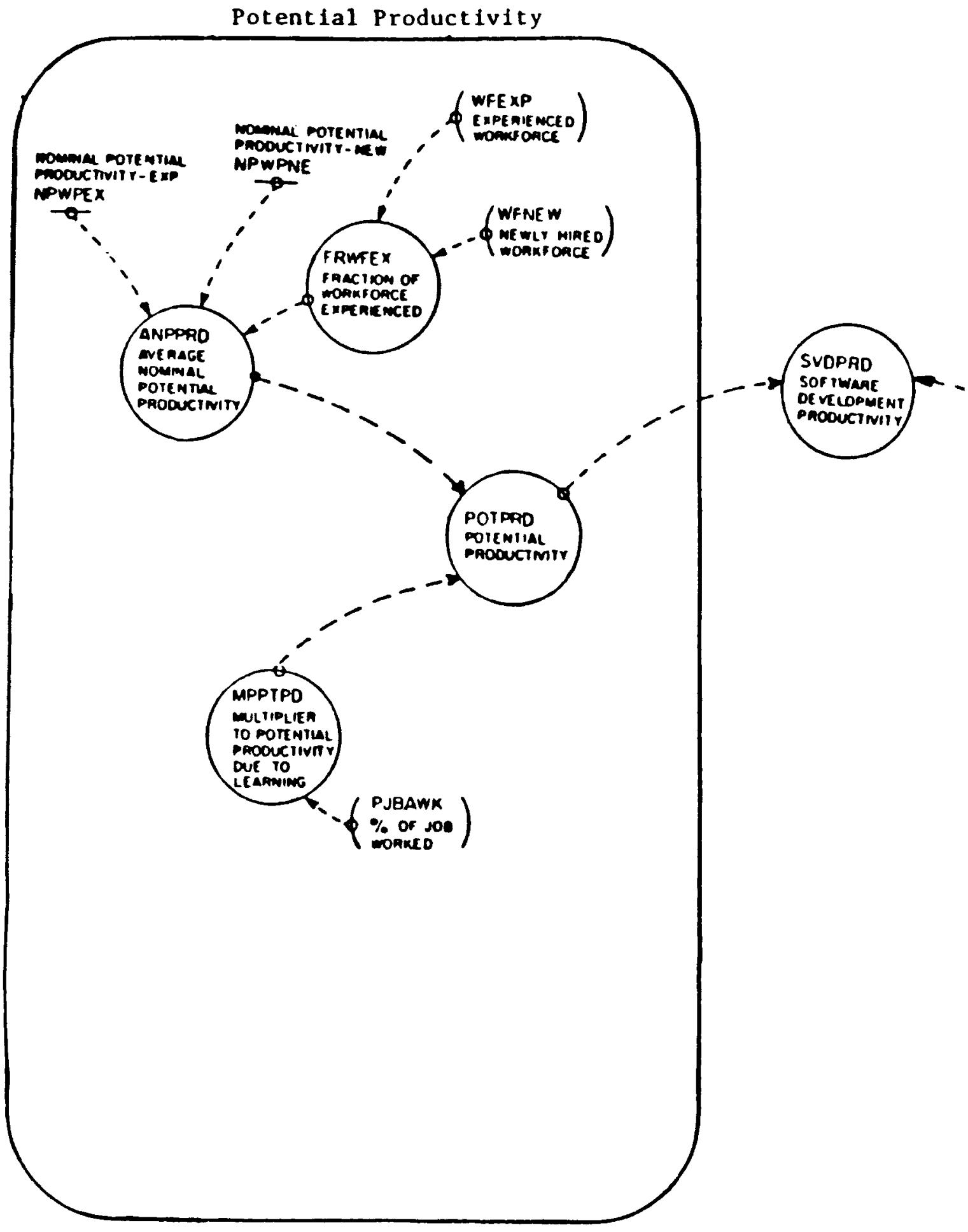




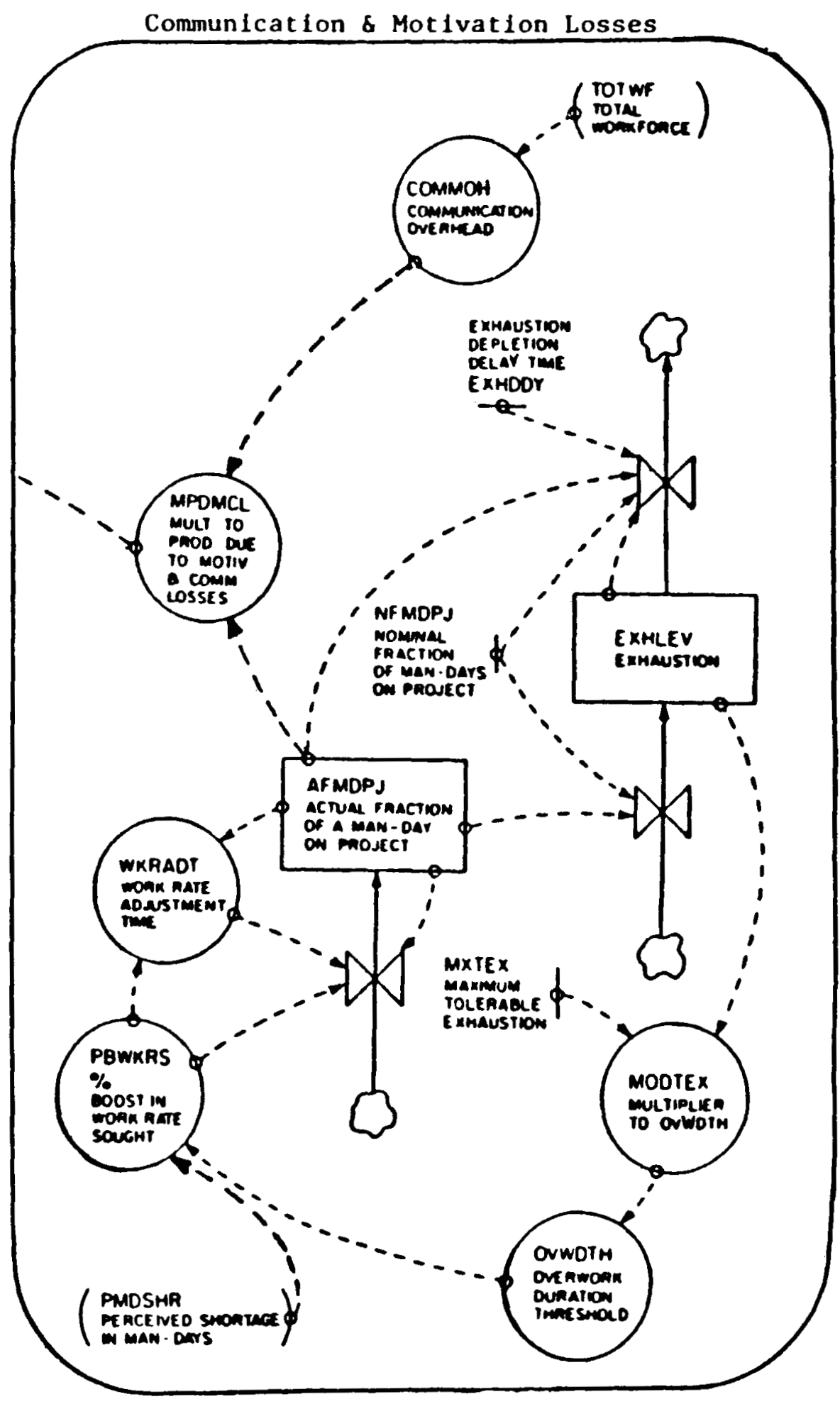

Fig. 2. Software productivity 
they tend to remain constant throughout the development lifecycle of any single project. From our viewpoint, this observation is quite significant. It means that in studying the dynamics of software productivity during the lifecycle of a software project, such factors can be assumed to remain constant. In the model, such factors are captured through the nominal potential productivity parameters, which represent the maximum level of software development productivity that can be attained for a specific project within a specific organization and for a specific employee type, whether new or experienced, at any point in the project.

Specifically, the average nominal potential productivity ANPPRD for the workforce as a whole is the weighted average of two nominal potential productivity parameters, one to represent the average nominal potential productivity of the experienced staff member NPWPEX and the second to represent that of the average newly hired employee NPWPNE. The latter is set to be half that of experienced staff members (Okada 1982; Thadhani 1984). The average nominal potential productivity changes throughout the lifecycle of the software project as the workforce experience mix changes.

A second dynamic factor affecting potential productivity is the increase in project know-how due to project-specific learning. As a project proceeds, project members learn to do their job better. The learning curve effect is formulated as the S-shaped (Weinberg 1982) multiplier to potential productivity due to learning MPPTPD. It starts with a value of 1 at the beginning of the project and peaks at 1.25 towards the end of the development period (Aron 1976).

LOSSES DUe to FAUlty pRocess. As defined above, potential productivity is the level of productivity attained when an individual or group makes the best possible use of available resources. Actual productivity, however, rarely equals potential productivity because of losses caused by communication and motivation overheads.

In the model, software development productivity SVDPRD is formulated as a product of potential productivity POTPRD and the multiplier to productivity due to communication and motivation losses MPDMCL. In the absence of any communication and motivation losses, the multiplier assumes a value of 1 , in which case actual productivity would be equal to potential productivity. However, losses will occur, and these will drive the multiplier to values that are less than 1.

The multiplier to productivity due to communication and motivation losses MPDMCL represents the average productive fraction of a man-day. For example, if the average communication and motivation losses amounted to three man-hours lost in a nominal eight-hour workday, then the value of the muliplier would be $5 / 8$, or 0.625 .

Motivation factors determine the fraction of a man-day devoted to project work. Since time is often lost on personal matters, coffee breaks, and other non-projectrelated activities, this fraction will usually have a value less than 1 . Communication losses take further cuts out of this fraction, as explained in detail below.

MOTIVATION LOSSES. To discern the dynamic effects of motivation losses on productivity, we distinguish between those factors that tend to remain constant during the 
life of any one project and those that change throughout the project lifecycle. Many of the motivational factors discussed in the literature, such as possibility for growth and advancement, level of responsibility, and salary, are factors that characterize the overall organizational setting and climate. In our formulation, such static factors are incorporated in the definition of the potential productivity parameters.

According to Bartol and Martin (1982), "Another motivation approach which is particularly appropriate to the data-processing area is goal setting." These authors suggest that project goals and schedules play an important motivational role throughout the life of a software project. This was corroborated by Boehm (1981), who found that schedule pressures and project deadlines can significantly affect the project members' slack time, which is the time lost on off-project activities such as coffee breaks, personal business, and non-project communication.

The nominal slack time is captured in the model by the nominal fraction of a manday on the project NFMDPJ, which represents the fraction of daily hours allocated to project-related work in the absence of unusual schedule pressures. In designating a value for this parameter, one can draw upon a large volume of research findings. The findings are clustered within the 50-70 percent range: 50 percent (Brooks 1978); 5060 percent (Pooch and Gehring 1980); 60 percent (Thadhani 1984); and 70 percent (Boehm 1981). On the basis of these findings, the value of NFMDPJ is set in the model at 60 percent. That is, in an eight-hour day, a full-time employee spends, on the average, $0.6 \times 8=4.8$ hours on project-related work.

This loss in productivity does not remain constant throughout the life of the project. The motivational effects of schedule pressure can move the actual fraction of a manday on project AFMDPJ to values both higher (under positive schedule pressure) and lower (under negative schedule pressure) than the nominal value of 0.6 .

POSITIVE SCHEDULE PRESSURES. Positive schedule pressures can arise whenever the project is perceived to be behind schedule. When confronted with such a situation, software developers tend to work harder by allocating more man-hours to the project in an attempt to compensate for the perceived "delinquency" and bring the project back on schedule (DePree 1984; Ibrahim 1978). In one experiment, Boehm (1981) found that the number of man-hours can increase by as much as 100 percent. He asserts that most of the gains are achieved by reallocating, or compressing, people's slack time. In other words, under increased schedule pressure, people tend to spend less time on off-project activities such as personal business and non-project communication. This increases the daily man-hours allocated to the project.

In addition to partly compressing their slack time, workers may also work overtime. For example, by working 12 hours per day at 80 percent efficiency, a team member allocates 9.6 hours to the project--double the nominal 4.8 hours. In fact, by further compressing the slack time (say to 10 or 15 percent) and further increasing the overtime hours, an increase in project man-hours per day of more than 100 percent could be achieved.

To recapitulate, when a project is perceived to be behind schedule, people tend to work harder to bring it back on schedule. They do so by compressing their slack time 
or by working overtime. But what if such a situation persists? Would workers be willing to work harder indefinitely? The answer, based on common sense and confirmed by our field study results, is overwhelmingly no. Our findings indicate that there is a threshold for how long employees are willing to work at an above-normal rate. Workers savor their slack time, and they typically will not tolerate a prolonged deprivation of such "breathers." Compressed slack time exhausts them (psychologically more so than physically) in the sense that it cuts into their tolerance level for continued overworking. Exhaustion (EXHLEV) and its effect on the work rate are portrayed explicitly in the model, as shown in Figure 2.

NEGATIVE SCHEDULE PRESSURES. Negative schedule pressures arise on those occasions when a project is perceived to be ahead of schedule, that is, when the total man-days remaining in the project's budget exceed what project members perceive to be needed to complete the project. This happens, for example, when management initially overestimates a project's complexity.

When project members perceive some excess time in the schedule, some of this excess time will tend to get absorbed by workers in the form of goldplating or "underwork" (DePree 1984; Ibrahim 1978). For example, "If the software cost or schedule estimate for meeting a milestone is higher than the ideal, Parkinson's Law indicates that people will use the extra time for . . . personal activities, catching up on the mail, etc." (Boehm 1981).

Analogous to the case of positive schedule pressure, where a threshold exists on how much overwork people could tolerate, there are limits on how much "fat" employees would be willing, or allowed, to absorb. Excesses beyond these limits will be translated into cuts in the project's schedule.

LOSSES DUE TO COMMUNICATION OVERHEAD. The value of the actual fraction of a manday on project AFMDPJ captures the losses in productivity due to motivational factors only. Additional losses in productivity due to communication overhead may be incurred.

What is communication overhead? To answer this question, consider the differences between developing software using a single person and developing it using a team of people. There are at least two differences. First, when software is developed by a single person, there is no time "lost" on project-related human communication. When, on the other hand, a team of software professionals develops software, communication overhead results:

It is necessary that each individual spend part of his time communicating with each of the other team members. For example, the designer must confer with the coder to resolve any questions the coder may have about the design; both of these must talk to the individual testing the code to give him the benefit of their experience with the program; each of these must talk to the documentor to assure that the documentation is proper and complete; and so on. (Tausworthe 1977)

Second, the amount of work itself usually increases when software is developed by a team rather than by a single person. For example, the amount of production 
documentation typically increases. In a one-person environment the programmer could get away with sketchy notes to merely augment his or her "mental documentation"; this would be intolerable in a team environment (Tausworthe 1977).

Communication overhead may be defined as the drop in productivity of the average team member caused by the overhead incurred in communicating, orally as well as in writing, with others on the project. The nature of the relation between communication overhead and team size has been investigated by several authors. It is widely held that communication overhead increases in proportion to $n^{2}$, where $n$ is the size of the team (Brooks 1978; Mills 1976; Scott and Simmons 1974; Shooman 1983; Zelkowitz 1978).

\section{Actual versus perceived productivity}

Decisions made in any organizational setting are based on what information is actually available to the decision makers. Often, this available information is inaccurate. Apparent conditions may be far removed from the actual or true state, depending on the information flows that are being used and the amount of time lag and distortion in these information flows (Forrester 1961).

True productivity of a software project team is a good example of a variable that is often difficult to assess. To know what the true value of productivity is at a particular point requires accurate knowledge regarding the rates of accomplishment of project work and resources expended over that period of time. However, software is basically an intangible product during most of the development process. "It is difficult to measure performance in programming. . . . It is difficult to evaluate the status of intermediate work such as undebugged programs or design specification and their potential value to the complete project." (Mills 1983)

How, then, is progress measured in a software project? Our own field study findings corroborate those reported in the literature, namely, that progress, especially in the earlier phases of software development, is typically measured by the actual expenditure of resources compared with the budgeted amounts rather than by some count of accomplishments (DeMarco 1982). Baber (1982) explains:

It is essentially impossible for the programmer to estimate the fraction of the program completed. What is 45 percent of a program? Worse yet, what is 45 percent of three programs? How is he to guess whether a program is $\mathbf{4 0}$ percent or 50 percent complete? The easiest way for the programmer to estimate such a figure is to divide the amount of time actually spent on the task to date by the time budgeted for that task. Only when the program is almost finished or when the allocated time budget is almost used up will he be able to recognize that the calculated figure is wrong.

When progress in software development is measured solely by the expenditure of resources, status reporting ends up being nothing more than an echo of the original plan. Under such circumstances, man-days perceived still needed for new tasks MDPNNT, which represents the amount of work still to be done, is simply equal to man-days perceived remaining for new tasks MDPRNT, which represents the budgeted resources remaining. This notion of productivity is captured in the model by 
the variable projected development productivity PJDPRD, where

PJDPRD $=\frac{\text { TSKPRM }}{\text { MDPRNT }}$

and TSKPRM is the value of tasks perceived remaining.

As the project advances towards its final stages, work accomplishments become relatively more visible and project members become increasingly more able to perceive how productive the workforce has actually been. As a result, perceived productivity gradually ceases to be a function of projected productivity and is determined instead on the basis of actual tasks developed. That is, perceived development productivity PRDPRD approaches the value of average development productivity AVGPRD, where

AVGPRD $=\frac{\text { Cumulative tasks developed }}{\text { Cumulative man-days expended }}$

The shifting between these alternative schemes for assessing software productivity can be obtained by appropriately adjusting the value of the weighting factor WTPJDP in the equation for perceived development productivity:

PRDPRD $=$ PJDPRD $*$ WTPJDP + AVGPRD $*(1-$ WTPJDP $)$

As the project progresses, the weighting factor WTPJDP gradually decreases from a value of 1 at the start of the project until it eventually becomes zero as the project approaches its final stages of development. The rate at which this happens is a product of two factors, namely, the rate of expenditure of resources and the rate of product development (Baber 1982). To accomplish this in the model, the weighting factor WTPJDP is formulated as the product of two multipliers: the multiplier to productivity weight due to resource expenditures, and the multiplier to productivity weight due to development. The shapes of the multipliers are functions of programming environment factors, such as the milestones used, the sophistication of programming tools, and the reporting procedures.

\section{Model behavior}

The EXAMPLE software project

We will use an EXAMPLE software project as the prototype for conducting model experimentation on software productivity.

Project EXAMPLE's size is selected to be 64,000 DSI. The value of the nominal potential productivity for the average experienced staff member is set to one task per man-day by definition, and the value of a task is 60 DSI. Thus, EXAMPLE's size in terms of tasks is $64,000 / 60=1,067$.

At the start of a software project, management must decide how much labor and time to allocate to the project. Such decisions are based not on the project's real size but rather on what its size is perceived to be, since the real size is often not known 
ig. 3. Project XAMPLE: base run verview

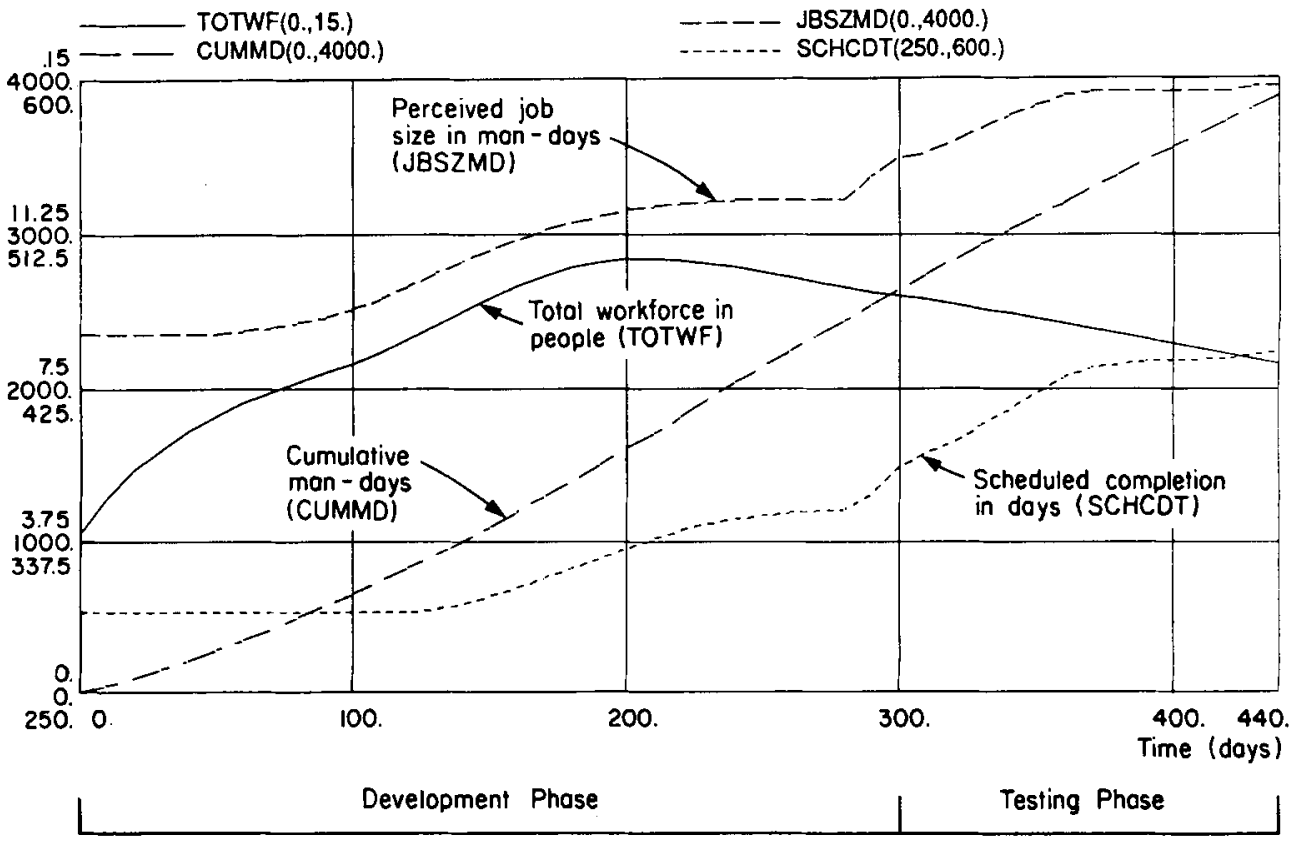

at the start. We assume that at its initiation, EXAMPLE's size was underestimated by 33 percent: the project was perceived to be only $0.67 * 64,000=42,880$ DSI in size.

This value is then used to estimate effort and schedule. One popular estimation tool is the COCOMO model (Boehm 1981). Using COCOMO produces the following estimates for EXAMPLE:

Development effort $=2,359$ man-days

Development time $=296$ days

Finally, the project's average staffing level is determined by dividing development man-days by development time, yielding a value of eight people. Not all eight people will be on board at the beginning of the project, however. Most software projects start with a small core of designers, and as the project proceeds, the workforce builds up to higher levels. In EXAMPLE, the project starts with a core of four experienced software personnel.

With these things accomplished, our model initialization procedure is complete. Figure 3 depicts the model's base case run over the 440 days actually required to complete the project. Four key measures of EXAMPLE's progress are shown: perceived job size in man-days, the total workforce level, cumulative man-days, and scheduled completion time.

As the job progresses and the scope of the effort becomes clearer, the perceived job size rises, ultimately leading to revisions in the scheduled completion date from its initial estimate of 296 days to its final value of 440 days. 
Fig. 4. Project EXAMPLE: potential productivity

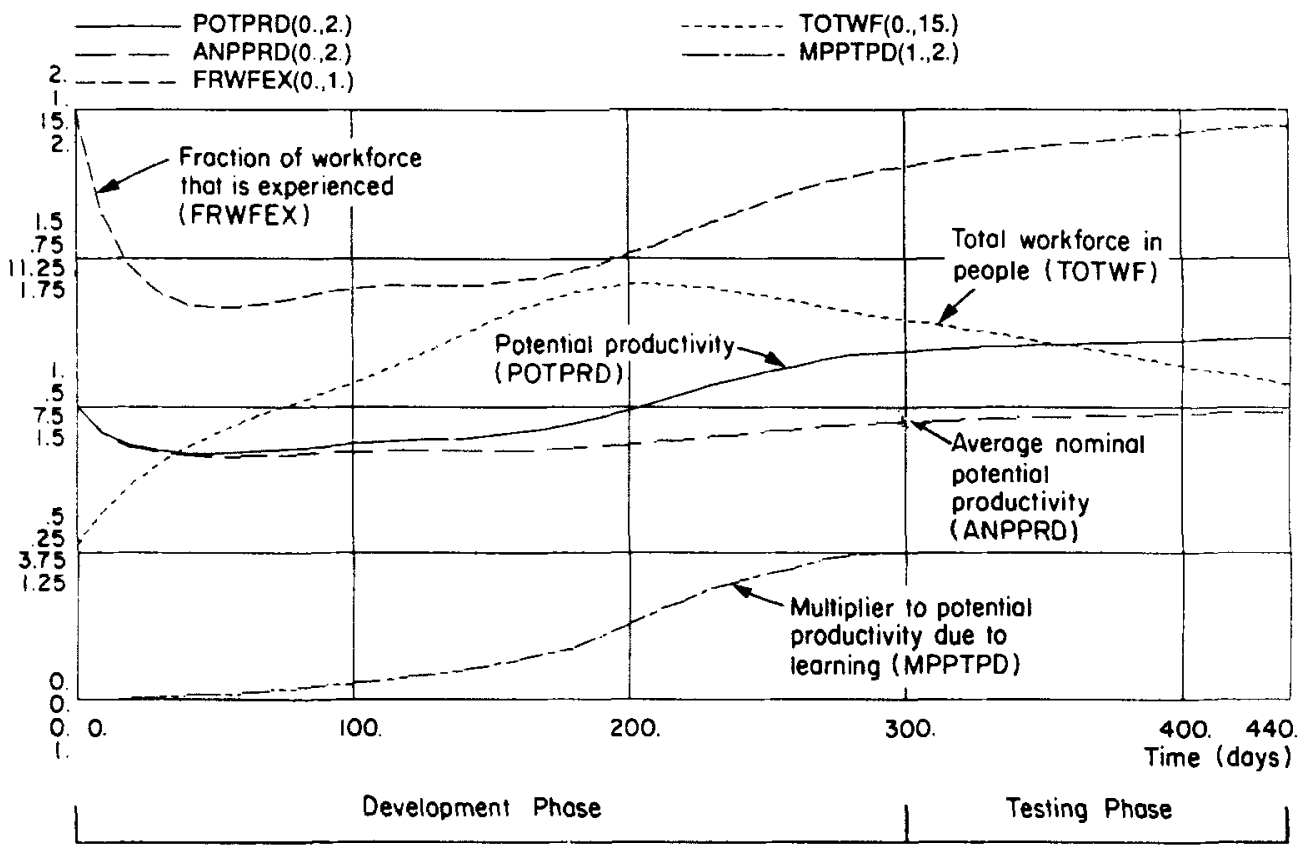

Actual/potential productivity gap

Figure 4 depicts the dynamic behavior pattern of factors determining potential productivity. Note the initial drop in average nominal potential productivity. This is caused by the buildup of the workforce from the small core of experienced people to a larger team of both experienced and (initially) inexperienced personnel. This drop is reversed as the newly hired team members are assimilated into the project and become experienced team members.

Initially, potential productivity follows the average nominal potential productivity curve. But, as the project proceeds, the workforce's potential productivity rises because of the increase in project-specific know-how gained through the learning-curve effect.

Figure 5 demonstrates the difference between potential productivity and actual productivity. There are two kinds of productivity losses incurred on the project. The first class of losses accounts for the gap between the potential productivity and actual productivity curves, while the second causes the additional drop of the average development productivity curve.

The first class of losses involves motivation and communication losses incurred on the project. As was explained earlier, communication overhead includes both oral and written communication (documentation) and increases proportional to the square of the workforce size. Motivation losses, on the other hand, are captured by the variable actual fraction of man-day on project AFMDPJ. Notice in Figure 6 that during the first half of the project's lifecycle, this variable assumes a steady value of 0.6 , 
Fig. 5. Project EXAMPLE: actual productivity

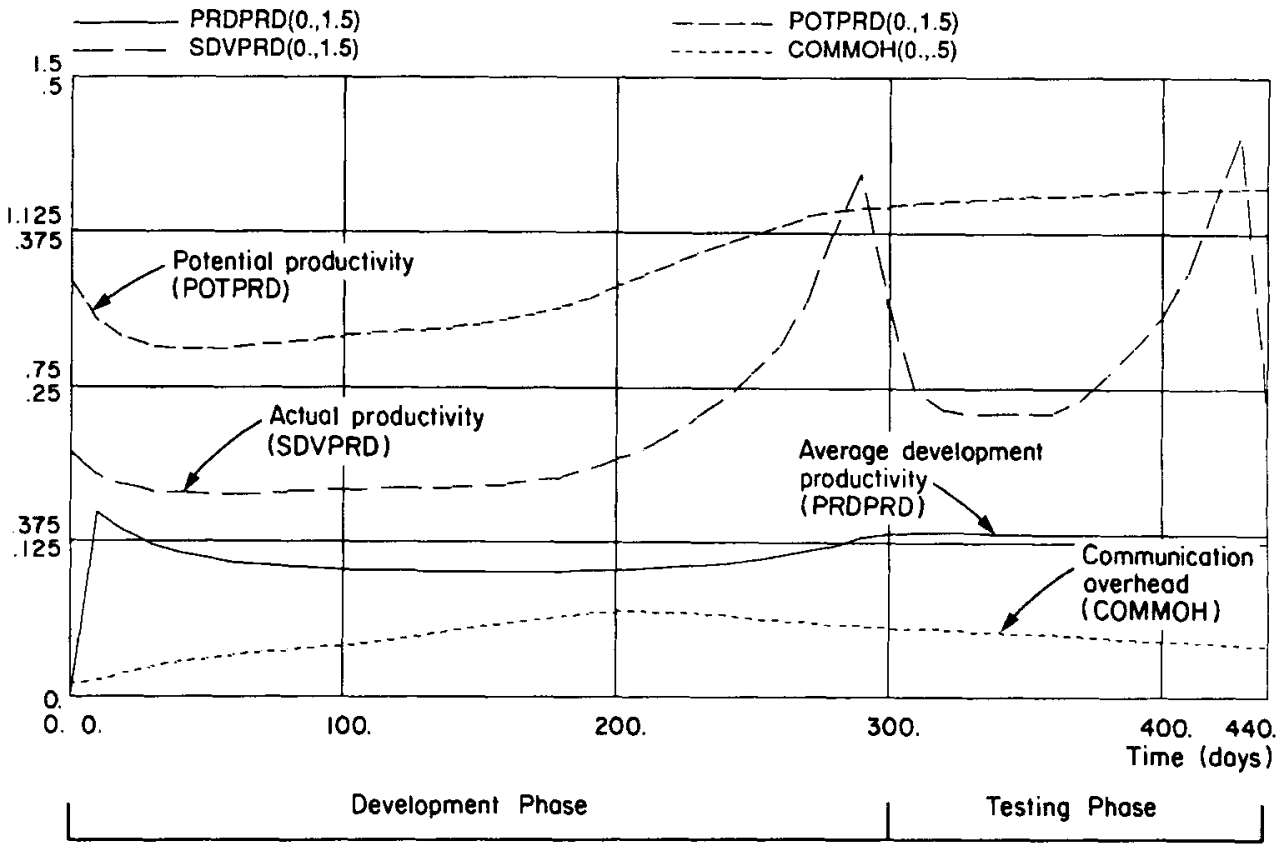

indicating that the team members are averaging $0.6 * 8=4.8$ hours per day on the project. Near the end of the development phase, though, a "spike" of overwork occurs. To understand the causes of this behavior, recall that when project EXAMPLE was started, its size was underestimated by 33 percent. Underestimating the project's size leads, in turn, to an underestimate of the required effort in man-days. This shortage in man-days does not, however, become visible until later in the development phase. When this happens, the team reacts by working harder in an attempt to bring the project back on schedule. Working harder translates into the higher values of actual fraction of man-day on project.

Under the intense pressure of an imminent deadline, actual fraction of man-day on project may exceed 100 percent because of dramatically reduced slack time and increased overtime work. This occurs during this development "spike," which is also reflected in the corresponding rapid rise in actual productivity. In fact, as shown in Figure 5, in this example, actual productivity exceeds potential productivity at the height of this peak, as the average worker contributes more than eight nominal productive man-hours per day.

Notice in Figure 6 that even as the project members are working harder, the shortage in man-days keeps rising because, as the development phase approaches its final stages, the degree of visibility increases rapidly, exposing even more previously undetected man-day shortages. Thus, although working harder, project members may appear to be falling behind because previously undetected tasks are being discovered faster than tasks are being completed. To highlight the significance of the workforce's contributions, we plotted a curve (labeled with asterisks) that depicts what the level 
Fig. 6. Project EXAMPLE: perceived shortage in man-days

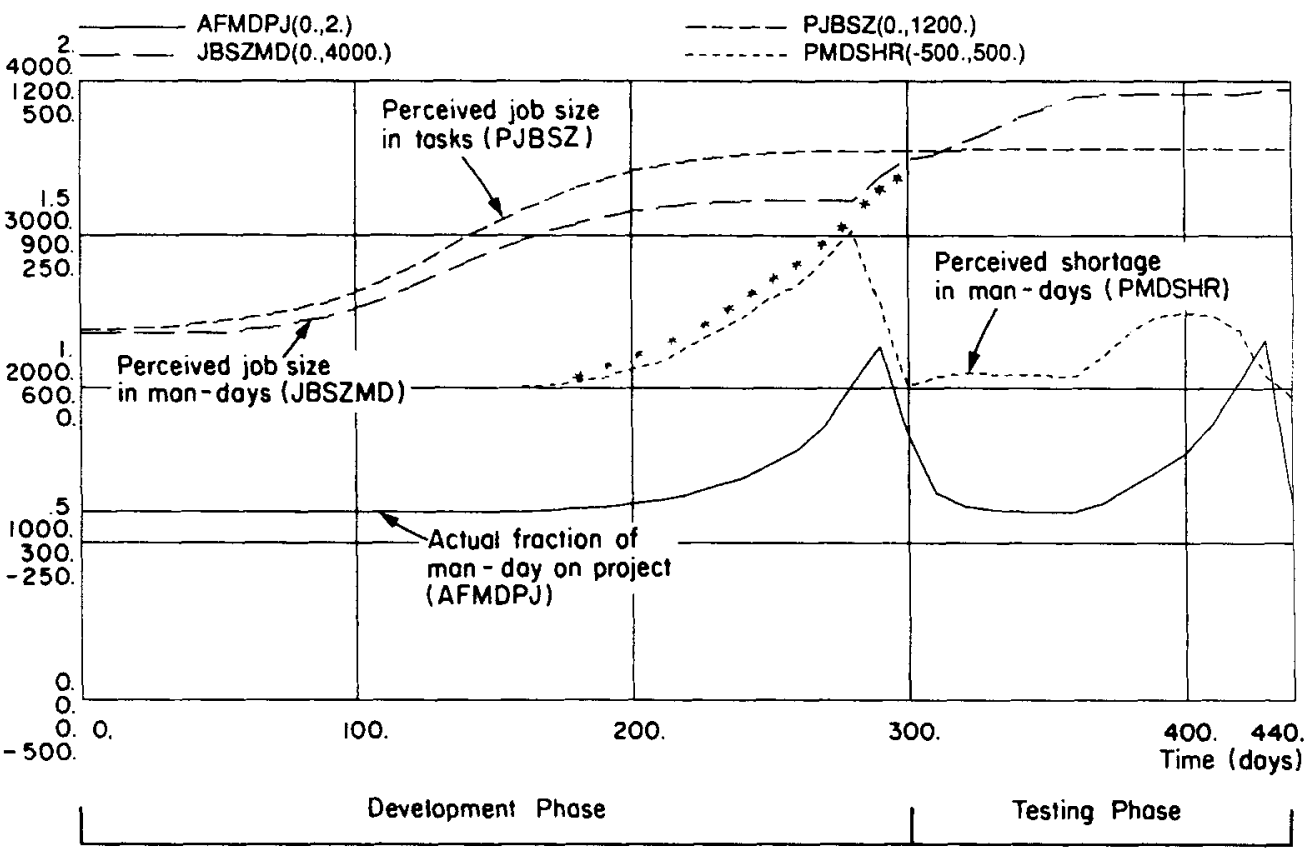

of the perceived shortage in man-days would have been if project members had maintained their normal (lower) work rate.

As was explained earlier, project members are typically unwilling to maintain an above-normal work rate indefinitely. Thus, as the backlog problem persists, it eventually overwhelms the workforce's intensified effort and, around day 300, arrangements are made to handle those remaining shortages through adjustments to both the project's man-days budget and its schedule. These adjustments can be seen in Figure 3.

In addition to the motivation and communication losses incurred, a further drain on a project team's productivity occurs as errors are committed and then need to be reworked. Thus, even though the instantaneous actual productivity might be a respectable $X$ tasks per man-day, the average development productivity will be lower, since some of the $X$ tasks developed must be redone. Rework, then, explains the gap between the two types of actual productivity shown in Figure 5, instantaneous and average.

\section{Perceived/actual productivity gap}

The discrepancy between perceived and actual productivity is demonstrated in Figure 7. As expected, in the early stages of the project the general pattern of the perceived productivity curve follows that of the projected productivity curve. Notice that while actual productivity (and potential productivity) are dropping slightly because of the buildup of newly hired members, perceived productivity is rising slightly. 
Fig. 7. Project EXAMPLE: perceived productivity

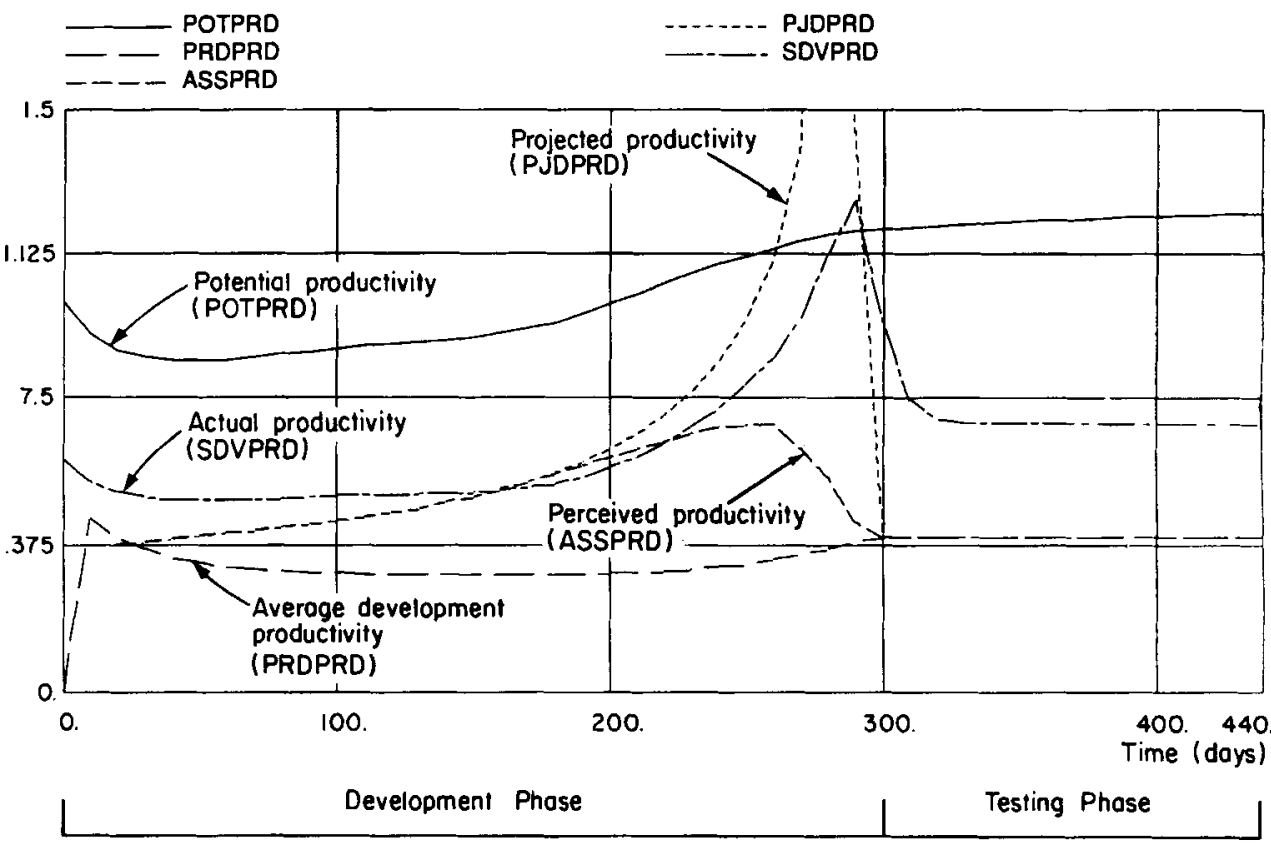

This initial rise in perceived productivity needs some explanation. Recall that, in the initial phases of the project, perceived productivity is a function of the ratio of tasks perceived remaining to man-days remaining. Recall also that EXAMPLE's size was initially underestimated by 33 percent. When additional tasks are gradually discovered during development, they do not necessarily trigger an adjustment to the project's man-day estimate, as we saw in Figure 3. Only when new tasks are discovered in "chunks" of significant size will project members go to the trouble of formally updating the cost estimates (Abdel-Hamid 1984). The determining factor is not the absolute size of the discovered tasks but their size relative to the amount of effort perceived remaining. For example, while a 100-man-day task discovered at the beginning of a 100,000-man-day project might not trigger any adjustments in the project's estimates, it would be quite likely to spur significant changes if discovered at the end of the development phase, when only 50 man-days remain.

When increases in the project's scope due to the discovery of new tasks are not fully reflected as increases in the project's man-days, the value of projected development productivity, and thus perceived productivity, rises. It is as if management were anticipating the coming need to reduce slack time.

As the project advances toward its final stages, and accomplishments become relatively more visible, project members become increasingly more able to perceive how productive the workforce has actually been. As a result, perceived productivity ceases to be a function of projected productivity and is determined instead on the basis of actual accomplishments, or average development productivity. As this happens, the gap between perceived productivity and average development productivity 
gradually narrows and is eventually closed. As noted earlier, because of the discovery of previously undetected tasks near the end of the development phase, the perceived productivity drops even while actual productivity is still rising. In other words, the harder the team works, achieving higher actual productivity, the faster previously undetected tasks are discovered. These additional tasks increase the amount of work left, partly canceling out the effect of tasks completed and leading to lower perceived productivity.

\section{Concluding remarks}

Software development productivity has become a critically important topic. Our objective in this article was to study the dynamics of software productivity during the development lifecycle of a software project. Our investigation discerned three forms of productivity: potential, actual, and perceived. This conceptual dissection of productivity provides a useful lens for investigating two important but distinct sets of managerial concerns: losses in the efficiency of software production, and losses in the effectiveness of managerial control.

Efficiency of software production (potential versus actual)

Losses in the efficiency of software production are incurred as a result of communication and motivation faulty processes. The larger the losses, the larger is the gap between potential productivity (for a particular project setting) and actual productivity.

The significant impact that communication overhead can have on software development projects is perhaps best illustrated by what Frederick Brooks called Brooks's Law, namely, that adding more people to a late software project can make it later because of the increase in the communication and coordination overheads (Brooks 1978). Brooks's insights are based on his experience in the development of IBM's OS/ 360 operating system and are therefore intended to apply to what he called "jumbo systems programming projects." We have investigated the applicability of Brooks's Law to medium-sized application-type software projects (Abdel-Hamid 1989). We found that, for such projects, adding manpower to a late project always increases the development cost in man-days, but it does not necessarily cause the project to finish later. In particular, we found that Brooks's Law applies only when the workforce additions are made quite late, near the end of the lifecycle. In any case, communication losses can exact a heavy toll on software development projects.

Project managers also must guard against motivation losses. For example, overestimating project resources can lead to significant losses in productivity due to goldplating and increases in nonproductive slack time activities. In our investigation of the common scheduling practice of using "safety factors" to inflate initial project estimates (Abdel-Hamid and Madnick 1986), the results indicated that such practices lead to larger and more costly projects than would have resulted had a safety factor not been used. 


\section{Effectiveness of managerial control (actual versus perceived)}

Losses in the effectiveness of managerial control are primarily caused by the poor level of progress visibility experienced in the earlier phases of software development. As a result, a significant discrepancy can arise between managerial perceptions and reality.

One consequence of this deficiency is the infamous 90 percent syndrome, which Baber (1982) describes as follows: "Estimates of the fraction of the work completed [increase] as originally planned until a level of about $80-90$ percent is reached. The programmer's individual estimates then increase only very slowly until the task is actually completed."

As was explained earlier, measuring progress in the initial phases of a project by the rate of expenditure of resources causes status reporting to be nothing more than an echo of the project's plan. This creates the illusion that the project is on target. However, as the project approaches its final stages-when 80-90 percent of the resources are consumed-discrepancies between the percent of tasks accomplished and the percent of resources expended become increasingly apparent. Furthermore, project members become increasingly able to perceive how productive the workforce has actually been. This results in a better appreciation of the amount of required effort actually remaining, often leading to increased schedule pressure or adjustments to the schedule.

Strategies for improving project visibility were investigated by Abdel-Hamid (1988). He found that a modest improvement in progress visibility in the early phases, using such techniques as project reviews and Computer-Aided Software Engineering (CASE) tools, can significantly reduce the 90 percent syndrome.

\section{Implications}

In order to address effectively the need to improve software development productivity, one must understand its various forms and the factors that influence them. This article provides a comprehensive structure for such an investigation as well as important preliminary findings.

\section{References}

Abdel-Hamid, T. K. 1984. The Dynamics of Software Development Project Management: An Integrative System Dynamics Perspective. Unpublished Ph.D. Dissertation, Sloan School of Management, M.I.T., Cambridge, MA 02139.

- 1988. Understanding the $90 \%$ Syndrome in Software Project Management: A Simulation-Based Case Study. Journal of Systems and Software (Sept.): 1-12.

1989. The Dynamics of Software Project Staffing: A System Dynamics Based Simulation Approach. IEEE Transactions on Software Engineering 15 (2): 109-119.

Abdel-Hamid, T. K., and S. E. Madnick. 1986. Impact of Schedule Estimation on Software Project Behavior. IEEE Software (July): 70-75.

— 1989. Software Project Management. Englewood Cliffs, N.J.: Prentice-Hall, forthcoming. 
Aron, J. D. 1976. Estimating Reasons for Large Programming Systems. In Software Engineering: Concepts and Techniques, ed. J. M. Buxton, P. Naur, and B. Randell. Litton Educational Publishing.

Baber, R. L. 1982. Software Reflected. New York: North-Holland.

Bartol, K. M., and D. C. Martin. 1982. Managing Information Systems Personnel: A Review of the Literature and Managerial Implications. MIS Quarterly (Dec.): 49-70.

Boehm, B. W. 1981. Software Engineering Economics. Englewood Cliffs, N.J.: PrenticeHall.

Brooks, F. P., Jr. 1978. The Mythical Man-Month. Reading, Mass.: Addison-Wesley.

Chrysler, E. 1978. Some Basic Determinants of Computer Programming Productivity. Communications of the ACM 21 (June): 472-483.

Cooper, K. G. 1980. Naval Ship Production: A Claim Settled and a Framework Built. Interfaces 10 (Dec.).

DeMarco, T. 1982. Controlling Software Projects. New York: Yourdon Press.

DePree, R. W. 1984. The Long and Short of Schedules. Datamation (June 15): 131-134.

Forrester, J. W. 1961. Industrial Dynamics. Cambridge, Mass.: MIT Press.

Gehring, P. F., Jr., and U. W. Pooch. 1977. Software Development Management. Data Management 15 (2): 14-18.

Graham, A. K. 1982. Software Design: Breaking the Bottleneck. IEEE Spectrum 19 (3): 4350.

Ibrahim, R. L. 1978. Software Development Information System. Journal of Systems Management (Dec.): 34-39.

Kelly, T. J. 1970. The Dynamics of R\&D Project Management. Unpublished M.S. Thesis, Sloan School of Management, M.I.T., Cambridge, MA 02139.

Lehman, M. M. 1978. Laws and Conservation in Large Program Evaluation. In Proceedings of the Second Lifecycle Management Conference, Atlanta, Ga.

McGowan, C. L., and R. C. McHenry. 1980. Software Management. In Research Directions in Software Technology, ed. P. Wegner. Cambridge, Mass.: MIT Press.

Mills, H. D. 1976. Software Development. IEEE Transactions on Software Engineering SE2 (Dec.): 265-273.

1983. Software Productivity. Boston: Little, Brown.

Musa, J. D. 1985. Software Engineering: The Future of a Profession. IEEE Software (Jan.): $55-62$.

Nay, J. N. 1965. Choice and Allocation in Multiple Markets: A Research and Development Systems Analysis. Unpublished M.S. Thesis, Dept. of Electrical Engineering, M.I.T., Cambridge, MA 02139.

Okada, M. 1982. Software Development Effort Estimation Study: A Model from CAD/CAM System Development Experiences. In Proceedings of IEEE International Computer Software and Applications Conference, Chicago.

Pooch, V. W. and P. F. Gehring, Jr. 1980. Toward a Management Philosophy for Software Development. In Advances in Computer Programming, ed. T. Rullo. Philadelphia: Heyden \& Sons.

Putnam, L. H. 1980. The Real Metrics of Software Development. EASCON (Electronics and Aerospace Systems Convention) 80.

Richardson, G. P. 1982. Sources of Rising Product Development Times. Technical Report D-3321-1, System Dynamics Group, M.I.T., Cambridge, MA 02139.

Richardson, G. P., and A. L. Pugh III. 1981. Introduction to System Dynamics Modeling with DYNAMO. Cambridge, Mass.: MIT Press.

Roberts, E. B. 1964. The Dynamics of Research and Development. New York: Harper and Row.

Roberts, E. B., ed. 1978. Managerial Applications of System Dynamics. Cambridge, Mass.: MIT Press. 
Scott, R. F., and B. D. Simmons. 1974. Programmer Productivity and the Delphi Technique. Datamation (May): 71-73.

Shooman, M. L. 1983. Software Engineering: Design, Reliability, and Management. New York: McGraw-Hill.

Snyder, C. A., and J. F. Cox. 1985. A Dynamic Systems Development Life Cycle Approach: A Project Management Information System. Journal of Management Information Systems 2 (Summer): 61-76.

Steiner, I. D. 1972. Group Process and Productivity. New York: Academic Press.

Tausworthe, R. C. 1977. Standardized Development of Computer Science. Englewood Cliffs, N.J.: Prentice-Hall.

Thadhani, A. J. 1984. Factors Affecting Programmer Productivity During Application Development. IBM System Journal 23 (1): 19-35.

Weinberg, G. M. 1982. Understanding the Professional Programmer. Boston: Little, Brown. Zelkowitz, M. V. 1978. Perspectives on Software Engineering. Computing Surveys 10 (June): 197-216. 